\title{
Papillary carcinoma thyroid presented with extensive local lymph nodal metastasis
}

\author{
Sunil V Jagtap ${ }^{1, *}$, Digvijay Patil ${ }^{2}$, Chetan ${ }^{3}$, Sonal O. Gupta ${ }^{4}$, \\ ${ }^{1}$ Professor, Dept. of Pathology, Krishna Institute of Medical Sciences, Karad Maharashtra, ${ }^{2}$ Associate Professor, Dept. of \\ Oncosurgery, Krishna Institute of Medical Sciences, Karad Maharashtra, ${ }^{\mathbf{3} 4}$ Assistant Lecturer, Dept. of Pathology, Krishna \\ Institute of Medical Sciences, Karad Maharashtra, India
}

*Corresponding Author:

Email: drsvjagtap@gmail.com

\begin{abstract}
Amongst thyroid malignancies papillary carcinoma is the most common form. It usually remains intrathyroid and carries good prognosis. In our care, it was presented with rapid onset of clinical manifestations within 2 months duration. A 54 years old male patient had history of change in voice, enlargement of thyroid with multiple cervical lymphnodes enlargement. On fine needle aspiration cytology, ultrasonography, computed tomography scan neck diagnosed as malignant thyroid lesion. He underwent total thyroidectomy with left cervical radical neck dissection. On histopathology showed invasive papillary carcinoma with extensive nodal metastasis.
\end{abstract}

Keywords: Thyroid carcinoma, Papillary carcinoma, Regional node metastasis.

\section{Introduction}

Papillary carcinoma is the most common type of thyroid carcinoma which comprises about $75-85 \%{ }^{1}$ Papillary carcinoma is typically slow growing malignant tumor. Many times, it remains asymptomatic. Also cases with silent thyroid nodule with significant local nodal enlargement were noted. In our case, it showed rapid clinical course with extensive regional lymph node involvement.

\section{Case Report}

A 54 years old male patient presented to oncosurgery department having history of change in voice since 2 months which got rapidly worsened and presented along with enlargement of thyroid. There was simultaneous multiple nodular masses notes on cervical region. On clinical examination, left thyroid lobe was enlarged, single nodular mass lesion measuring $1.5 \times 1.0 \mathrm{~cm}$ and multiple left cervical nodules. The larger was measuring $3 \times 2 \times 1 \mathrm{~cm}$. Patient was apparently alright 2 months back. He has been suffering from systemic illness of hypertension and diabetes mellitus for 3 years and getting regular treatment. He had no history of radiation, any immunological disorder or thyroid disease before 2 months. On radiological examination, ultrasonography of neck reveled left thyroid lobe enlargement with hypoechoic, lobulated mass with calcification and peripheral vascularity measuring 1.6 x $1.3 \times 1.0 \mathrm{~cm}$. It was suggestive of malignant mass lesion. Also left cervical nodes level I, II, III showed evidence $\mathrm{S} / \mathrm{O}$ metastasis.

Multislice computed tomography scan showed ill defined, partially calcified nodular lesion in the upper pole of left hemithyroid measuring $1.7 \times 1.0 \mathrm{~cm}$. The lesion was hypodense and remains hypoenhancing on post contrast images. Multiple enlarged left level I, II, III, IV, V and VI lymphnodes noted. Largest measuring $3.4 \times 3.3 \times 1.5 \mathrm{~cm}$. Calcification was noted. Radiologically diagnosed as suggestive of malignant neoplasm with nodal metastasis. There was no evidence of any distant metastasis. On FNAC reported as papillary carcinoma thyroid.

Patient underwent total thyroidectomy with left cervical radical dissection. On gross left thyroid lobe showed mass measuring $1.9 \times 1.3 \times 1.0 \mathrm{~cm}$. On cut open showed solid, grey white, papillary lesion. Areas of cyst formation, hemorrhage focal calcification was noted (Fig. 1). Left cervical lymphnodes mass was noted. Largest measuring $3.4 \mathrm{x}$ $3.3 \times 1.5 \mathrm{~cm}$ (Fig. 2). On histopathology diagnosed as invasive papillary carcinoma thyroid with lymphnode metastasis (Fig. 3, 4). Patient responded well to treatment and advised regular follow up.

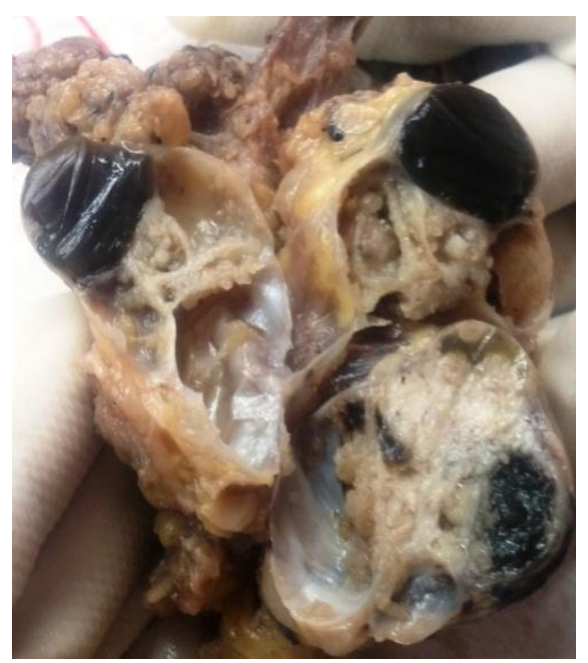

Fig. 1: Gross thyroidectomy specimen showing solid cystic papillary tumor 


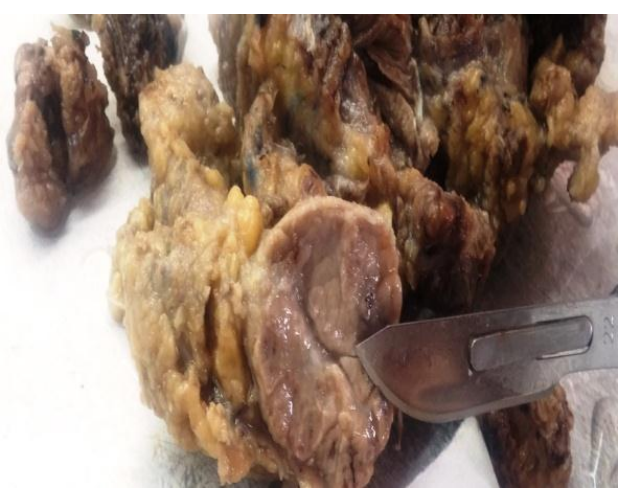

Fig. 2: Gross specimen of radical lymph node dissection showing metastases

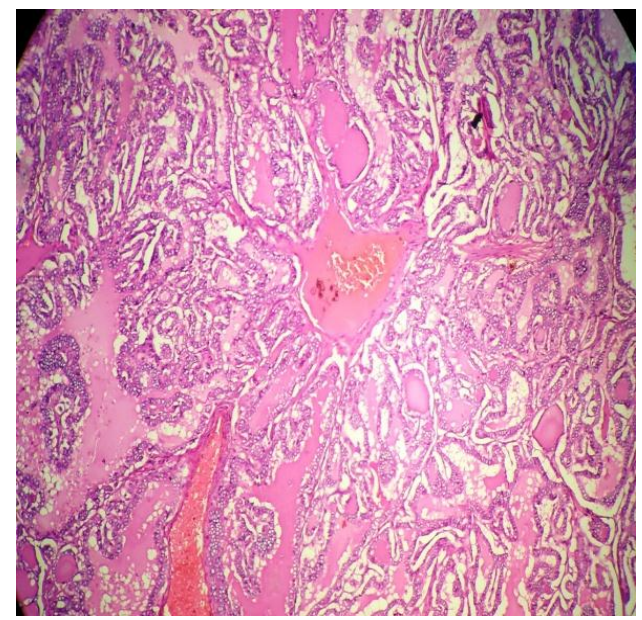

Fig. 3: Papillary carcinoma of thyroid (Haematoxylin \& eosin stain, $10 \mathrm{x}$ )

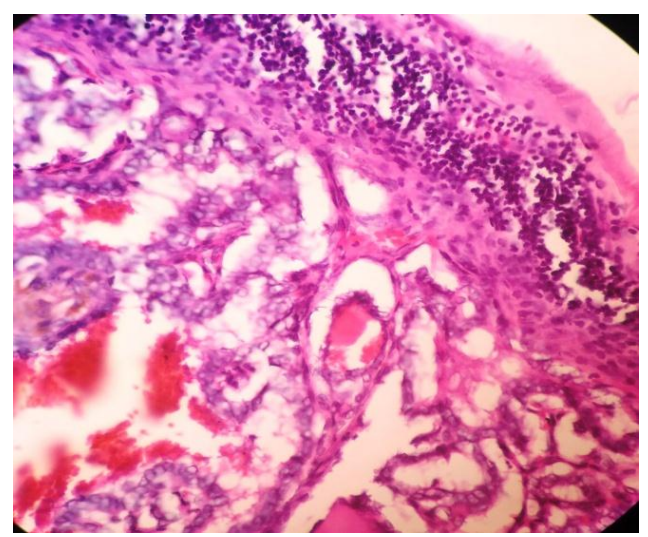

Fig. 4: Papillary carcinoma metastasis in lymphnode (Haematoxylin \& eosin stain stain, 40x)

\section{Discussion}

Papillary carcinoma of thyroid is common thyroid malignancy with good prognosis. It is seen 2 times more in females as compared to male. ${ }^{2}$ The tumors are diagnosed in $3^{\text {rd }}-5^{\text {th }}$ decade of life. ${ }^{3}$ Many times, patient remains asymptomatic and may present as nodal metastasis. Occult tumors are noted upto 24 $\%$ of cases. ${ }^{4}$ Majority of cases show progress of tumor with often asympyomatic solitary nodule. In our case, it was presented with short duration history with rapid cervical lymphnode involvement. The tumor size is small as compared to nodal masses. The common etiological factors are early age exposure to neck radiation, excess iodine, exposure to nuclear explosion, Hashimoto's thyroiditis and familial occurrence etc. In our case no such association was noted.

On gross examination, tumor appears solid, firm, encapsulated or diffusely infiltrative. Areas of calcification, fibrosis, cyst, hemorrhage, scaring were noted. In $20 \%$ cases multifocal tumor is noted. ${ }^{5}$

On FNAC, papillary carcinoma shows branching papillae with fibrovascular core. The lining cells are cuboidal with nuclear overlapping. The nuclei are having typical optically clear nuclear chromatin (Orphan Eye Nuclei), nuclear grooves. ${ }^{6}$ Psamomma bodies, spindle cell metaplasia, stromal fibrosis and associated Hashimoto's thyroiditis were seen.

On histopathological findings above features are noted along with subtypes like tall columnar diffuse sclerosing, solid and follicular variants have been described. Our case showed all routine features, however there was no associated metaplasia, fibrosis or Hashimoto thyroiditis.

The regional lymphnode metastasis is observed in $29-40.9 \%$ cases. $^{7,8}$ The distant metastasis is rare and seen in $10-15 \%$ of cases. The sites are lungs, bones, liver, central nervous system. ${ }^{9,10}$

Papillary carcinoma is biologically indolent and have an excellent prognosis. However older age at diagnosis, larger tumor size, presence of metastasis, male sex and on histopathology poorly differentiated, vascular/lymphatic invasion and certain subtypes (tall columnar diffuse subtype) of papillary cases have poor prognosis. ${ }^{11}$

\section{Conclusion}

We reported a case of papillary carcinoma of thyroid which showed aggressive clinical course. It suggested although the papillary carcinoma is slow growing tumor with good prognosis, in this case appropriate treatment with removal of metastatic regional lymphnodes are important for better prognosis of patient.

\section{References}

1. Rosai J, Carcangui ML, DeLellis RA. Tumors of the Thyroid Gland. Atlas of Tumor Pathology, Fascicle 5. Armed Forces Institute of Pathology: Washington, DC, 1992.

2. Enewold L, Zhu K, Ron E, et al. Rising thyroid cancer incidence in the United States by demographic and tumor characteristics 1980-2005. Cancer Epiodemiol Biomarkers Prev 2009;18:784-791.

3. Baloch Z, LiVolsi VA. Pathology of the thyroid gland. In: Livolsi VA, Asa S (eds). Endocrine Pathology. Churchill Livingston: Philadelphia, PA, 2002, pp 6188. 
4. McConahey WM, Hay ID, Woolner LB, van Heerden JA, Taylor WF. Papillary thyroid cancer treated at the Mayo Clinic, 1946 through 1970: Initial manifestation, pathologic findings, therapy and outcome. Mayo Clin Proc 1986;61:978-96.

5. Carcangui ML, Zampi G, Pupi A, et al. Papillary carcinoma of the thyroid: a clinico-pathologic study of 241 cases treated at the University of Florence, Italy. Cancer 1985;55:805-828.

6. Baloch ZW, LiVolsi VA, Asa SL, et al. Diagnostic terminology and morphologic criteria for cytologic diagnosis of thyroid lesions: a synopsis of the National Cancer Institute Thyroid Fine-Needle Aspiration State of the Science Conference. Diagn Cytopathol 2008;36:425437.

7. El-Foll HA, El-Sebaey HI, El-Kased AF, Hendawy A, Kamel MM Pattern and Distribution of Lymph Node Metastases in Papillary Thyroid Cancer. J Clin Exp Pathol 2015; 5:204.
8. McConahey WM, Hay ID, Woolner LB, Heerden JA, Taylor WF. Papillary thyroid cancer treated at the Mayo Clinic, 1946 through 1970: initial manifestations, pathologic findings, therapy and outcome. Mayo Clin Proc.,1986;61:978-96.

9. Hoie J, Stenwig AE, Kullmann G, Lindegaard M. Distant metastases in papillary thyroid cancer: a review of 91 patients. Cancer 1988;61:1-6.

10. SV Jagtap, VC Aher, SS Jagtap, RS Khandelwal. Cytopathological study of lymphadenopathies in malignant lesions: an institutional study. International Journal of Medical and Health Sciences 2016,3,154-157.

11. Moreno-Egea A, Rodriquez-Gonzalez M, Sola-Perez J, et al. Multivariate analysis of histopathlogical features as prognostic factors in patients with papillary thyroid carcinoma. Br Surg 1995;82:1092-1095. 